\title{
Provocación por desafíos: Experiencia optimizadora del abordaje de tareas matemáticas con alta demanda cognitiva
}

\author{
Provocation by Challenges: Optimizing Experience of Addressing Mathematical Tasks With \\ High Cognitive Demand
}

\section{Provocação por desafios: Experiência otimizadora na abordagem de tarefas matemáticas com alta demanda cognitiva}

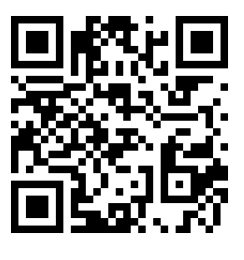

Recibido • Received $\cdot$ Recebido: $11 / 10 / 2018$

Corregido • Revised $\cdot$ Revisado: 13 / $03 / 2020$

Aceptado • Accepted $\cdot$ Aprovado: 03 / 08 / 2020

Resumen: Las tareas matemáticas de alta demanda cognitiva implican ejercer habilidades para analizar, inferir, relacionar y reflexionar sobre la información aritmética, geométrica y estadística. En su desarrollo, el compromiso del estudiantado es crucial para superar situaciones cada vez más complejas en el proceso de aprendizaje del sistema escolar peruano. Estas variables son de vital importancia, debido a que el estudiantado necesita evitar influencias negativas que provoquen el fracaso o la deserción académica, por lo que es valioso vivir experiencias de mejora motivacional de su conducta matemática para llegar al éxito permanente en esta área. En esta propuesta, el objetivo fue comprobar, con base en la teoría de Flow (fluencia), si los efectos de una experiencia de provocación por desafíos optimizaban el abordaje de tareas matemáticas con determinada demanda cognitiva. El diseño fue de tipo cuantitativo preexperimental. Se incluyó una muestra de 76 estudiantes. El instrumento fue la prueba de problemas aritméticos con demanda cognitiva múltiple. Los resultados permitieron concluir que el programa estimuló la solución de tareas memorísticas y problemas con información no conectiva, pero su efecto fue menor y más lento en el abordaje de tareas de alta 
http://doi.org/10.15359/ree.24-3.9

http://www.una.ac.cr/educare

educare@una.ac.cr

demanda cognitiva. El estudio contribuyó a comprobar las bondades del andamiaje basado en estrategias de fluencia (Flow), de acuerdo con los desafíos y retos que estimulan la independencia cognitiva del estudiantado que aprende a abordar tareas cognitivas, en concordancia con la experticia y compromiso obtenidos mediante la interacción con el personal docente o mediador.

Palabras claves: Andamiaje; demanda cognitiva; desafío; educación matemática; tarea.

Abstract: High cognitive demand mathematical tasks involve exercising skills to analyze, infer, relate and reflect on arithmetic, geometric and statistical information. In its development, student engagement is crucial to overcome increasingly complex situations in the learning process of the Peruvian school system. These variables are of vital importance because students need to avoid negative influences that cause academic failure or dropout, so it is valuable to live experiences of motivational improvement of their mathematical behavior to achieve permanent success in this area. In this proposal, the objective was to check whether the effects of a challenge provocation experience, based on Flow's theory, optimized the approach to mathematical tasks with a certain cognitive demand. The design was of a pre-experimental quantitative type. A sample of 76 students was included. The instrument was the test of arithmetic problems with multiple cognitive demand. The results allowed concluding that the program stimulated the solution of memory tasks and problems with non-connective information, but its effect was less and slower in addressing tasks with high cognitive demand. The study contributed to verifying the benefits of scaffolding based on flow strategies, according to the challenges that stimulate the cognitive independence of the student who learns to tackle cognitive tasks, in accordance with the expertise and commitment obtained through interaction with the teacher or mediator.

Keywords: Scaffolding; cognitive demand; challenge; Mathematics education; homework.

Resumo: As tarefas matemáticas cognitivamente exigentes envolvem o exercício de habilidades para analisar, inferir, relacionar e refletir sobre informações aritméticas, geométricas e estatísticas. Em seu desenvolvimento, o compromisso dos estudantes é crucial para superar situações cada vez mais complexas no processo de aprendizagem do sistema escolar peruano. Estas variáveis são de vital importância, pois os estudantes precisam evitar influências negativas que provoquem fracasso acadêmico ou desistência. Portanto, é valioso viver experiências de melhoria motivacional de seu comportamento matemático a fim de alcançar sucesso permanente nesta área. Nesta proposta, o objetivo era verificar, com base na teoria do Fluxo, se os efeitos de uma experiência de provocação de desafio otimizavam a abordagem de tarefas matemáticas com certa demanda cognitiva. $\mathrm{O}$ projeto foi de um tipo quantitativo pré-experimental. Foi incluída uma amostra de 76 estudantes. O instrumento foi o teste de problemas aritméticos com demanda cognitiva múltipla. Os resultados nos permitiram concluir que o programa estimulou a solução de tarefas memorizadas e problemas com informações não-conectivas, mas seu efeito foi menor e mais lento na abordagem de tarefas com alta demanda cognitiva. O estudo contribuiu para provar os benefícios da estrutura baseada em estratégias de fluxo, junto aos desafios que estimulam a independência cognitiva dos estudantes que aprendem a abordar tarefas cognitivas, de acordo com a expertise e o compromisso obtidos através da interação com o corpo docente ou mediador.

Palavras-chave: Plataforma; demanda cognitiva; desafio; educação matemática; tarefa. 
http://doi.org/10.15359/ree.24-3.9

\section{Introducción}

Las tareas matemáticas de índole escolar son procedimientos que mejoran el procesamiento cognitivo cuando se superan distintos niveles de dificultad en matemáticas, esta superación permite evidenciar el progreso de los tipos de pensamiento: geométrico, estadístico y aritmético. Su abordaje suele ser un constante estresor en la comunidad escolar. Se origina debido al procesamiento de estructuras complejas de las tareas, sobre todo en el área matemática, comunicación y ciencias. Por un lado, las tareas de demanda cognitiva básica exigen la inclusión de datos que determinan un primer nivel de solución; por otro, las tareas de alta demanda implican el uso de habilidades de asociación de la información textual mediante procesos interactivos de aprendizaje. Es allí donde el estudiantado peruano demuestra ciertas debilidades conforme enfrenta las tareas académicas $y$, al no encontrar la solución, la demanda cognitiva les provoca la confrontación del estrés y un entramado de soluciones que, a fin de cuentas, recargan la memoria operativa y afectan el rendimiento durante el proceso educativo anual. Ante esto, la investigación se centró en los procesos que realiza el estudiantado al enfrentarse a tareas con demanda cognitiva, donde comprobara su logro de aprendizaje y manifestara el sentido de superación mediante la sensación de sentirse motivado por experiencias de optimización (Flow). Esto redundaría en conocer, si el aprendizaje progresivo, en estas condiciones, les permitió abordar mayores niveles de complejidad matemática.

\section{Antecedentes e hipótesis}

Las investigaciones centradas en tareas de alta demanda cognitiva se relacionan con las de actitud docente, con fines de desarrollo cognitivo en la escuela. Estas han puesto preocupación en el logro de la conexión de información que realiza el estudiantado al enfrentarse a tareas específicas como la resolución de operaciones y de problemas (Ayllón et al., 2016; Benedicto et al., 2015; Burgos, 2017; Cirino de Jesús, 2011; Dávila y Trujillo, 2016; Mateus Nieves, 2015; Ponce et al., 2010), en el desarrollo de aptitudes en la resolución de operaciones aritméticas (Cirino de Jesús, 2011; Dávila y Trujillo, 2016; Burgos et al., 2017); y en la comprensión de proposiciones en la resolución de problemas (Ayllón et al., 2016; Burgos et al., 2017; Ponce et al., 2010). Esto parte desde la dificultad para desarrollar procesos analíticos en el estudiantado y, seguramente, por los procesos conectivos que necesitan al relacionar una información con otra. Aquí también es compleja la relación entre la capacidad de operacionalizar la información literal, hacer inferencias en problemas y proporcionar la solución al problema con distintas connotaciones. Es en este momento cuando los niños y las niñas emplean, de forma genérica, sus habilidades: suelen fallar ante la presencia de otros factores de transformación de información, no advierten la dificultad para construir el sentido proposicional de la información matemática, como tampoco logran resolver consignas que implican la atención como medio esencial para utilizar 
http://doi.org/10.15359/ree.24-3.9

http://www.una.ac.cr/educare

educare@una.ac.cr

información muy específica. En este caso, la hipótesis es que la puesta en función de estas capacidades se ve influenciada por otras capacidades superiores necesarias como la relación de información y la selección de datos externos a las tareas; esto ocurre, necesariamente, en la resolución de problemas (Baroody, 2000; Godino et al., 2004; González, 2013; Stein et al., 2009). La demanda cognitiva permite estudiar componentes de aprendizaje en el estudiantado peruano; componentes con problemas muy comunes para su logro: estructuración de ideas, transformación de códigos, comprensión de consignas o, por último, en la resolución de operaciones aritméticas (Baroody, 2000; Godino et al., 2004). En el caso de la dificultad de las tareas, su abordaje con determinada demanda cognitiva exige el reconocimiento de las propiedades de las estructuras proposicionales del problema matemático (Baroody, 2000; Stein et al., 2009): detalles literales, información implícita (concreta y abstracta) y estructuras oraciones. La evidencia del estudiantado sobre esto provoca su pensamiento complejo activo. Por todo lo vertido hasta aquí, los supuestos serían:

a) los niños y las niñas abordan de igual modo toda tarea compleja sin analizar la integralidad proposicional de su complejidad (Figura 1)

b) los niños y las niñas que abordan tareas específicas perciben, sienten y discriminan la dificultad, pero sucumben ante esta sin utilizar otras soluciones diversificables

c) la ineficacia provocada por el uso constante de tipos de solución inservible se transmite en el retén memorístico a otras tareas más o menos complejas a abordar.

Este último supuesto es el más crucial, ya que su ejercicio en el desarrollo de competencias durante el curso de matemáticas genera distorsión en el uso de estrategias o habilidades ejecutivas insostenibles ante determinada complejidad matemática (Aguirre-Leguizamo, 2016; Canet-Juric et al., 2016; Defaz, 2017; Scattarética Muñoz, 2017); y finalmente, provoca fracaso en su posterior enfrentamiento a otras tareas con mayor demanda cognitiva.

\section{Problemática del estudio}

Las evaluaciones realizadas por la Unidad de Gestión de la Calidad Educativa en el Ministerio de Educación, Perú (Minedu, 2016b) desde antes del año 2015 demostraron que el $53 \%$ de escolares de segundo grado del Perú realizan tareas de tipo memorístico, gran cantidad ejecuta tareas sin conexión de información (64\%), y un máximo del 30\% en tareas con uso de información relacional o por procedimientos conexos. Esta realidad a nivel nacional describe a estudiantes cuyos procesos son esquemáticos, estructurales y faltos de asociacionismo en problemas con proveen distintas fuentes de información matemática; y en el caso de las tareas básicas que el profesorado de aula desarrollan, solo provocan el pensamiento vertical (Figura 1). 
http://doi.org/10.15359/ree.24-3.9

http://www.una.ac.cr/educare educare@una.ac.cr

Figura 1: Ejemplificación de operaciones en forma vertical en inicios del nivel primaria*

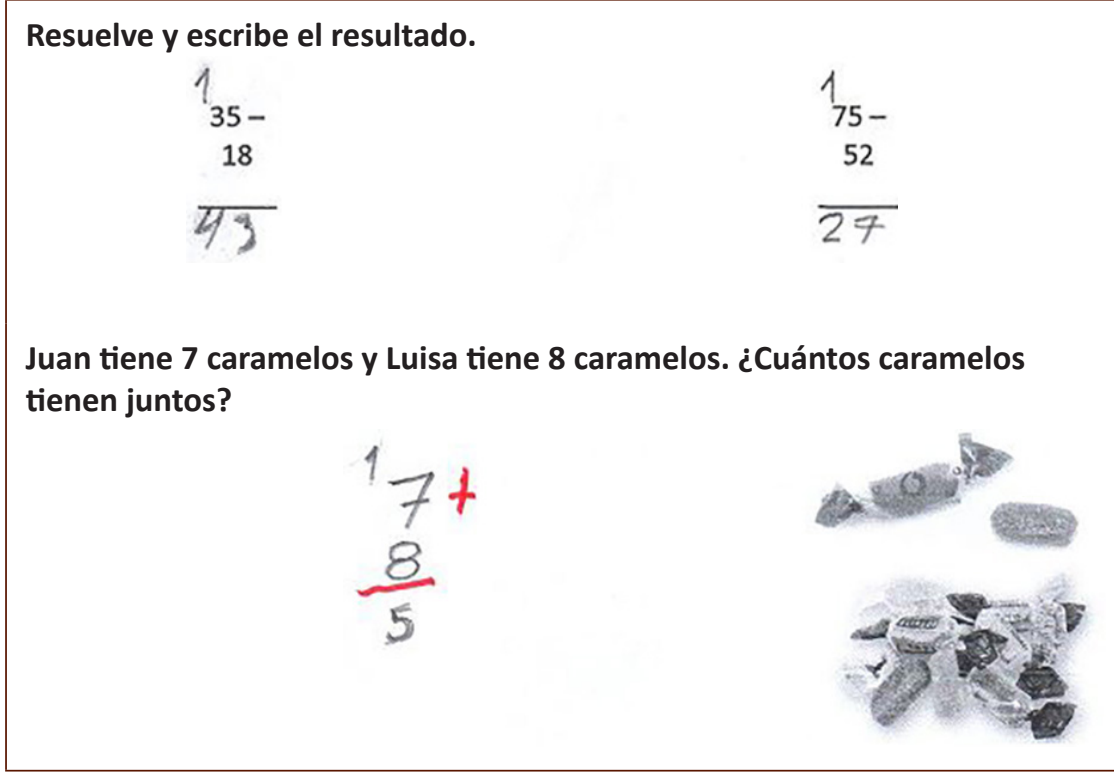

*El estudiantado que inicia el nivel primario de Educación Básica Regular, por lo general, desarrolla operaciones en forma vertical, y siguen pasos estructurados como: llevar, contar, recontar; y solo la transformación de las cantidades es necesaria para transformar códigos y asignar cantidades resultantes a operaciones: 7 (lleva 1$)+8=1 \ldots 5$. De similar manera, ocurre con la sustracción: un proceso lento.

Nota: Elaboración propia.

El pensamiento vertical es aquel comprendido como la capacidad para aplicar habilidades desde la información escrita, genera análisis basados en los significados literales del texto, lo provoca en el sujeto el uso de información sin relacionarla: conocida como la capacidad de utilizar información cerrada y convencional (Budiarto et al., 2017; Butto Zarzar y Delgado, 2019; Caviedes-Barrera et al., 2019; Sosa Moguel et al., 2020; Suh y Seshaiyer, 2015), sobre todo, en la búsqueda de soluciones. Shulman (1986 en Caviedes-Barrera et al., 2019) permite aducir que este tipo de conocimiento se sitúa en una condición de conocimiento del contenido (Subject Matter Content Knowledge, SMCK), por cuanto es el nivel que implicaría menor recarga en la memoria operativa y en el trabajo de las funciones cognitivas relacionales (comprensión e interpretación textual). Más adelante, a partir del año 2008, Ball et al. (en Caviedes-Barrera et al., 2019), lo consideraron como conocimiento común del contenido (Common Content Knowledge, $(C K)$. Esta funcionalidad es la que tiene más semejanzas a los procedimientos con demanda cognitiva de memorización. 
http://doi.org/10.15359/ree.24-3.9

http://www.una.ac.cr/educare

educare@una.ac.cr

Pensar de forma vertical o verticalmente es un problema estudiantil que ha afectado desde antes de las evaluaciones realizadas por el "Programa para la Evaluación Internacional de Estudiantes (PISA)" de la Organización para la Cooperación y el Desarrollo Económico (OCDE) desde antes del año 2000 (OCDE, 2015). Un problema muy específico son las operaciones que realiza el estudiantado ante alguna tarea cognitiva que demanda revisar distintas fuentes, ya sean estas inferenciales o literales, pues al estructurar el significado proposicional (información numérica desde el plano literal), otras habilidades se ponen en juego, como contar, clasificar, predecir, comprobar. Esta modalidad de realizar el aprendizaje ha sido instaurada en los métodos pedagógicos del profesorado, en principio, ya que la dificultad de programar es seguir pautas brindadas por el Minedu en el sistema de escolarización peruana (Holguin-Alvarez et al., 2019; León y Youn, 2016; Sanz, 2015). Esto ha desatado modalidades de enseñanza muy precarias, las cuales también son verticalistas o tradicionales para desarrollar el pensamiento matemático mediante el enfoque por competencias que se desea desarrollar en el sistema educativo peruano (Minedu, 2016a), el cual aún guarda complejidad para instaurarse en la metodología docente actual.

\section{Marco teórico}

\section{Tareas matemáticas de alta demanda cognitiva}

Las tareas con alta demanda cognitiva se consideran ejercicios, prácticas u operaciones de constitución teórica, práctica o de tipo teórico práctica. Estos implican el uso de capacidades o habilidades para su resolución. Las tareas matemáticas de alta demanda cognitiva son aquellas que implican el uso de habilidades cognitivas para recurrir a fuentes de información sin relacionarse entre sí, o, a fuentes diversas de información que el sujeto relaciona para lograr solucionar ejercicios, tareas o práctica en el área de matemáticas con determinado nivel de exigencia en la memoria operativa o en otras capacidades de procesamiento de la información (Aguirre-Leguizamo, 2016; Caviedes-Barrera et al., 2019; Stein et al., 2009), ya sea en el campo de la aritmética, geométrica o estadística (Aguirre-Leguizamo, 2016; Ayllón et al., 2016; Canet-Juric et al., 2016; Caviedes-Barrera et al., 2019; Suh y Seshaiyer, 2015). Estas también implican el uso de recursos o habilidades reflexivas para regular los procesos de resolución de estas operaciones (Aguirre-Leguizamo, 2016; Ayllón et al., 2016; Suh y Seshaiyer, 2015). La complejidad del proceso de solución de las tareas matemáticas también requiere procesos afectivos y actitudinales que impliquen estabilidad cognitiva. El verdadero problema del grupo estudiantil se relaciona en muchas oportunidades con procesos orientados al logro de soluciones mediadas por factores como tiempo, dificultad de la tarea, estilo de solución y reflexión. Aunque la complejidad que al solucionar se aborda en las tareas cognitivas, pues se incrementan paulatinamente mientras se adquiere mayor experiencia, es importante advertir que el fracaso se convierte en un fortalecedor de habilidades de monitoreo y reflexión. Esto se facilita al abordar tareas de alta demanda, las cuales exijan mayor uso de otras capacidades como las de relación comprensiva, inferencias y meta cognición. Maruja Dionisia Baldeón de la Cruz, Jhon Holguin-Alvarez y Gloria María Villa-Córdova

Los artículos de la Revista Electrónica Educare del Centro de Investigación y Docencia en Educación de la Universidad Nacional, Costa Rica, se comparten bajo términos de la Licencia Creative Commons: Reconocimiento, № Comercial, Sin Obra Derivada 3.0 Costa Rica. Las autorizaciones adicionales a las aquí delimitadas se pueden obtener en el correo: educare@una.cr 
http://doi.org/10.15359/ree.24-3.9

Siguiendo la clasificación desde los años 80 de Doyle (1983; 1988), las tareas fueron agrupadas acorde a los elementos básicos que utilizan los solucionadores para resolver tareas matemáticas con demandas cognitivas específicas: a) por el uso de la adopción de información y recuperación mediante la capacidad de memorizar, y, b) búsqueda de soluciones mediante la aplicación del razonamiento. Sin embargo, la clasificación de Stein et al. (2009) permitió declarar tareas con baja y alta demanda cognitiva acorde con la actividad que el sujeto realiza con la información, o con la interrelación de múltiples fuentes que utiliza para interrelacionar ideas matemáticas.

\section{Tareas de memorización o evocación}

Es una tarea de baja demanda cognitiva que implica el uso de información literal, descrita en la memoria por la capacidad de evocación o recuerdo de información previa (Georgius, 2013; Ni et al. 2014; Ni et al., 2018). El desarrollo de las tareas de memorización implica utilizar la información previa del almacén o retén informacional con el fin de solucionar operaciones matemáticas uniformes y cuya resolución se basa en la transformación de signos a elementos concretos. Por lo general, en este caso se desarrollan tareas con la única consigna de obtener resultados y la persona lectora se guía por comandos verbales directivos para su resolución: Resuelve y completa: Un ángulo recto vale... grados /... centímetros equivalen a 1 metro / 1/4 representa ...\%.

\section{Tareas procedimentales sin conexión}

Las tareas procedimentales suelen plantearse como ejercicios con consignas que implican el uso de bajo nivel de demanda cognitiva. La demanda cognitiva de este nivel provoca poco flujo para la resolución de operaciones y la información leída tiene bajo poder de relación entre los significados (Ni et al., 2018; Stein et al., 2009). Por lo mismo, invitan a generar algoritmos y transposiciones constructivas de información abstracta desde la comprensión de símbolos y cantidades, como por ejemplo: Resuelve y escribe el resultado: 35 - 18=... / Completa la operación para obtener el resultado: $15+\ldots=18$. En estos casos, el alumnado resuelve mediante el uso de información que, si bien es cierto transforma significados concretos desde la comprensión de simbologías (estadio abstracto de aprendizaje), sigue empleando información literal del texto, pero sobre todo, sin relacionarla a otras situaciones problemáticas.

\section{Tareas conectivas}

En Ni et al. (2018) se describe lo siguiente: Requerir al alumno que haga la conexión entre procedimientos y conceptos, o entre conceptos, o entre representaciones, por lo cual, estas tareas conectivas o tareas con conexiones son aquellas que exigen el uso de habilidades básicas: conocer, reconocer, comparar, y de habilidades más complejas: organizar/clasificar, discriminar y representar. Aquí el estudiantado utiliza la información mediante dos mecanismos de resolución: a) analizando conceptos, b) realizando transformaciones de conceptos. En este caso, la tarea de alta demanda cognitiva se ejecuta cuando el sujeto comprende la información, la utiliza y la transforma (hacer igualaciones, convierte datos, reutiliza datos). 
http://doi.org/10.15359/ree.24-3.9

http://www.una.ac.cr/educare

educare@una.ac.cr

\section{Tarea hacer matemática}

Las tareas de este tipo sugieren el acto de supervisión (regulación), comprobación, reflexión y poder de creación, a partir de la resolución de alguna operación matemática con estructuras complejas. Los teóricos especialistas en demanda cognitiva han planteado la distribución de tres tareas esenciales de con la utilidad de la información (Barriteau Phaire, 2013; Georgius, 2013; McCormick, 2016; Mwadzaangati, 2019; Ni et al. 2014; Ni et al., 2018; Stein et al., 2009): memorización, procedimiento sin conexiones, procedimientos con conexiones. Sin embargo, ante las exigencias de la etapa contemporánea, se consideran los aportes que implican la combinación de distintas fuentes de información mediante el uso de capacidades para la superación de obstáculos en el rendimiento académico (Mwadzaangati, 2019; Ni et al., 2018). Entre estas pueden considerarse: la comprensión relacional, la adaptación y flexibilidad a los procesos complejos de aprendizaje. Estas tareas se relacionan con las destrezas que necesita desarrollar el estudiantado en el nivel educativo primario acorde al Currículo Nacional de Educación Básica del Perú (Minedu, 2016a): a) obtener información del texto escrito, b) inferir e interpretar, c) reflexionar o evaluar, d) traducir datos (e) comunicar la comprensión matemática, f) usar estrategias, g) argumentar.

Hacer matemática es la tarea cognitiva que exige su resolución como también la comprensión de dicha resolución, es decir, mantener el estado regulador de la resolución y mediante la reflexión plantear nuevas situaciones teórico-prácticas en el alumnado.

\section{Provocación por desafíos: El estado de Flow}

La teoría del flujo o fluencia (Flow) define al estado de equilibrio que desarrollan los grupos participantes en distintas interacciones (verbales, escritas, visuales) por medio de la regulación emocional ante algún evento de interacción (Csikszentmihalyi, 1998a; 1998b; M. Csikszentmihalyi e I. S. Csikszentmihalyi, 1998; Csikszentmihalyi, 2014), mediante el cual se origina el compromiso hacia dicha interacción y aparece el planteamiento de objetivos, el compromiso hacia la tarea o eventualidad (Wu y Lin, 2017; Yeh y Lin, 2018), sea de forma consciente o inconsciente. Esta etapa de adopción del compromiso genera placer en la realización de dicha interacción o actividad (tarea o procedimiento).

En el ámbito académico, sobre todo en el área de competencia matemática, el abordaje de tareas cognitivas desarrolla habilidades, las cuales, de uno u otro modo generarían factores de desmotivación, desestimación y rechazo cuando la complejidad aumenta en las tareas con alta demanda cognitiva. En este caso, la provocación de la resolución de tareas complejas se basa en el estado de Flow (experiencia óptima) o estabilización cognitiva, provocado con el estímulo de los sistemas atencionales hacia el disfrute y control en el estudiantado cuando se enfrente a tareas dinamizadas (Csikszentmihalyi, 1998a, b; Csikszentmihalyi e I. S. Csikszentmihalyi, 
http://doi.org/10.15359/ree.24-3.9

1998; Nakamura, 1998). El estado de Flow (experiencia óptima o de optimización) determina la capacidad de estabilización en el ser humano ante situaciones emocionales en este tipo de complejidades matemáticas. Algunas de las exteriorizaciones de equilibrio se manifiestan en el control de los estados mentales al incrementar el interés en ellos. Este estado de equilibrio entre ambos polos ("negativos y positivos") ante una tarea "aburrida" permitiría que el estudiantado genere compromisos ante la resolución de alguna tarea compleja. La predisposición hacia la diversión por aprender dispone al estudiantado a reservar los límites entre actitudes con distinta valencia emocional: entre la diversión y el aburrimiento, la excitación y la tristeza, el ánimo y el desánimo. Estos procesos se logran en la escuela desde el uso de situaciones retadoras, desafíos y dinamizadoras de la actividad académica. Los eventos acompañantes o estimuladores del proceso de aprendizaje permiten al estudiantado activar otros procesos necesarios para abordar complejidades en la tarea matemática, como la regulación, monitoreo y autoevaluación.

Los estudios empíricos han aplicado el estado de Flow orientados hacia la formación de comportamiento (Challco et al., 2016; Mesurado, 2008), conductuación y movilización intercultural (Aubrey, 2016; Bettencourt, 2017), rendimiento ante el ejercicio estudiantil (Garces-Bacsal et al., 2011; Ersöz y Eklund, 2017); y se ha investigado en el abordaje cognitivo que se establece en el logro de la autodeterminación y autoeficacia mediante el juego (Yeh y Lin, 2018). Finalmente, se acepta que la experiencia óptima u optimización, en el caso de tareas de alta demanda cognitiva, establece el optimismo en su realización (Hong, 2017; Makvandi et al., 2018; Sedigh Srouni et al., 2016; Wu y Lin, 2017). En este estudio se considera que su estimulo sería de tipo longitudinal o permanente en el alumnado, desestimando los factores potenciales que origina la sociedad en el propio compromiso del estudiantado ante la tarea académica o actitudinal.

En el caso de las tareas cognitivas en escolaridad básica, no se han elaborado propuestas para su abordaje. Aquí, el logro del control permite reafirmar el equilibrio versus el desequilibrio ante la complejidad de la tarea matemática que el estudiantado aborda. En dicho proceso, la experiencia de optimización le permite abordar el problema, superar la recarga cognitiva, ampliar la capacidad de la memoria a largo plazo, encontrar soluciones posibles por ejecución o práctica, con el fin de verificarlas. El resultado permitiría aceptar el desencadenamiento del estado del optimismo para abordar posteriores tareas con similar demandas cognitivas más complejas.

Por lo anterior, se propone un estudio experimental para comprobar, si la provocación por desafíos basada en la teoría de Flow (experiencia óptima) permite que el estudiantado de segundo grado de escolaridad básica aborde, de forma positiva, las tareas matemáticas de alta demanda cognitiva y las solucionen con efectividad, luego de recibir sus beneficios. 
http://doi.org/10.15359/ree.24-3.9

http://www.una.ac.cr/educare

educare@una.ac.cr

\section{Objetivos}

El objetivo de la investigación fue determinar los efectos de la incursión en experiencias de provocación de la optimización cognitiva (Flow), por aplicación de técnicas dinamizadoras, motivacionales y reguladoras en el abordaje de tareas matemáticas con distinto nivel de demanda cognitiva que realiza el estudiantado entre siete y ocho años de edad (segundo grado de primaria) en el área de matemática. A su vez, se propone como objetivo específico verificar si este aprendizaje se provoca en tareas particulares como: a) memorización, b) procedimientos matemáticos sin conexiones, c) procedimientos con conexiones, y, d) hacer matemática (alta demanda).

\section{Método}

El estudio fue cuantitativo, de diseño experimental, nivel explicativo (Bologna y Urrutia, 2011; Campbell y Stanley, 2011; Hernández Sampieri et al., 2014), puesto que se buscó describir las causas y efectos de la aplicación de un programa experimental de provocación de Flow mediante andamiaje de tipo estudiante-docente (variable independiente) en la demanda cognitiva matemática (variable dependiente). El tipo de estudio fue el preexperimental, en función de su metodología, realizada mediante dos evaluaciones: a) pretest (aplicación del instrumento antes de la ejecución del programa), b) postest (aplicación del instrumento al finalizar el programa).

\section{Sujetos}

La muestra se conformó por 76 estudiantes de segundo grado de escolaridad básica de instituciones educativas de Lima ( $x=7,56$ años de edad). La participación del estudiantado fue de ambos géneros ( masculino $=56 \%$; femenino $=44 \%$ ). Los sujetos del estudio fueron seleccionados con los siguientes criterios de muestreo (caracterización) de inclusión: a) Desempeño en el área de matemática de nivel de proceso e inicio $(E B R)^{1}$, b) presentar condiciones cognitivas y afectivas estables, d) estudiantes con edades de siete a ocho años de edad hasta dos meses antes de la aplicación del instrumento del estudio. Los criterios que permitieron excluir a algunos individuos del experimento fueron: a) problemas de conducta disruptivos; b) problemas en relación con dislexias o discalculias de nivel moderado.

Respecto a los criterios de inclusión, se tuvo en cuenta el registro de rendimiento del personal docente tutor a cargo de cada sección a las que pertenecían los participantes; en cuanto a la condición cognitiva y afectiva se recurrió al análisis preliminar de diagnóstico (reporte psicológico) realizado por el departamento de psicología de las instituciones implicadas

\footnotetext{
${ }^{1}$ Desempeños de Educación Básica Regular (EBR) establecidos por el Ministerio de Educación del Perú.
} 
http://doi.org/10.15359/ree.24-3.9

en el estudio. En razón a la edad, se recurrió a la nómina de estudiantes proporcionada por la dirección de cada escuela. En cuanto a los criterios de exclusión, se consultó a cada docente sobre el comportamiento de cada estudiante, tomando en cuenta que se excluirían los datos obtenidos del estudiantado que cometiera conductas disruptivas (interrupciones en la clase del docente, agresividad colectiva, conflictos) hasta dos meses antes de comenzar el experimento. Las discalculias o dislexias fueron descartadas por profesionales en psicología al inicio del año lectivo mediante diagnóstico psicopedagógico. El porcentaje de estudiantes con esta condición fue muy ínfimo. Cabe señalar que la totalidad de integrantes de la muestra participó del consentimiento informado antes del desarrollo del estudio.

\section{Instrumento}

La resolución de operaciones, situaciones problemáticas y eventos con determinado nivel de complejidad (demanda cognitiva) exigió establecer pruebas que permitieran captar el rendimiento en matemática de forma escalonada. Es decir, fue necesario evitar el uso de pruebas dicotómicas, con las cuales únicamente se supiera si desarrollaban el ejercicio o no lo hacían, por cuanto se elaboró la Prueba de problemas aritméticos con demanda cognitiva múltiple (PRODECM), una prueba compuesta por 16 ítems, elaborada con el fin de evaluar tareas (dimensiones) clasificadas acorde con la demanda cognitiva: a) memorización, b) procedimientos sin conexiones, c) procedimientos con conexiones y d) hacer matemática (alta demanda). El instrumento se compuso por distintos ejercicios (tareas): operaciones, resolución de problemas y composición de consignas. El nivel estándar planteado para la elaboración de la prueba fue acorde con los desempeños establecidos por el Minedu (2016a), orientados al desarrollo de capacidades establecidas en el perfil de egreso de segundo grado de primaria, en correspondencia al del Currículo Nacional de Educación Básica (Tabla 1).

El instrumento se calificó con tres puntuaciones en operaciones con posibilidades de hasta tres opciones de respuesta: $0=$ no resuelve, $1=$ resuelve un ejercicio o plantea soluciones; y $2=$ plantea soluciones a las operaciones, resuelve el problema o crea nuevas consignas. Otros ítems fueron calificados de forma binomial (error $=0$ puntos; acierto $=1$ punto). La versión final, que se explica más adelante, se conformó por 11 ítems. Esta prueba se pasó a cinco personas evaluadoras de la validez de contenido (criterios evaluados: pertinencia, claridad, adecuación). Tres eran docentes con especialidad en didáctica de la matemática para la atención en instituciones educativas públicas y privadas; dos profesionales en metodología y especialistas de dos universidades de Lima (Perú). El promedio de aceptación por ítem fue mayor a 95\%, y en el total del instrumento mayor a una tasa de $95.6 \%$, por lo que el instrumento fue considerado válido. 
http://doi.org/10.15359/ree.24-3.9

http://www.una.ac.cr/educare

educare@una.ac.cr

Tabla 1: Ítems pertenecientes a la prueba PRODECM*

\begin{tabular}{|c|c|c|}
\hline \multirow[t]{2}{*}{ Categorías de tareas } & \multirow[t]{2}{*}{ Ítems } & Relación a los desempeños del Currículo Nacional Básico \\
\hline & & Áreas: matemática y comunicación \\
\hline Memorización & 1. Completa la frase: & Evoca datos. \\
\hline $\begin{array}{l}\text { Indicador: evocación mental } \\
\text { de cantidades. }\end{array}$ & $\begin{array}{l}\text { Juan tiene tres manzanas y se encontró una en el } \\
\text { cambio al colegio. Al inicio tenía... }\end{array}$ & Recupera información literal. \\
\hline Memorización & 2. Resuelve mentalmente: & \multirow[t]{2}{*}{ Realiza algoritmos en sustracciones y adiciones } \\
\hline $\begin{array}{l}\text { Indicador: suma mental } \\
\text { algorítmica }\end{array}$ & $\begin{array}{l}20+2=\ldots \\
8-5=\ldots\end{array}$ & \\
\hline Procedimentales no conectivas & 3.. Completa la frase: & Establece relaciones de datos literales \\
\hline $\begin{array}{l}\text { Indicador: suma mental por } \\
\text { lectura literal }\end{array}$ & $\begin{array}{l}\text { José tenía } 26 \text { canicas. Luego, jugando futbol } \\
\text { perdió } 6 \text {. Entonces tiene... }\end{array}$ & Establece relaciones de valor a cantidades \\
\hline \multirow{3}{*}{$\begin{array}{l}\text { Procedimentales no } \\
\text { conectivas } \\
\text { Indicador: suma mental por } \\
\text { lectura deductiva }\end{array}$} & 4. Lee y completa... & \multirow{3}{*}{$\begin{array}{l}\text { Realiza deducciones } \\
\text { Representa cantidades mediante deducciones } \\
\text { básicas }\end{array}$} \\
\hline & $\begin{array}{l}\text { Luisa ha obtenido } 10 \text { cuadernos en total, si al } \\
\text { inicio tenía } 5 . . . \text { entonces: }\end{array}$ & \\
\hline & $5+\ldots=10$ & \\
\hline \multirow{5}{*}{$\begin{array}{l}\text { Procedimentales conectivas } \\
\text { (alta demanda cognitiva) }\end{array}$} & \multirow{5}{*}{$\begin{array}{l}\text { 5. Lee y completa: } \\
\text { Juan es un joven que siempre desayuna una lata } \\
\text { de atún por las mañanas. El día martes abrió } 2 \\
\text { latas para desayunar junto a su gato. } \\
\text { Entonces: } \\
\text { - Su gato come al día__. } \\
\text { - Juan necesitará trabajar para comprar__latas } \\
\text { de atún a la semana. }\end{array}$} & \multirow{5}{*}{$\begin{array}{l}\text { Representa cantidades por inferencias } \\
\text { Establece relaciones entre datos de tipo: cambio, } \\
\text { continuidades, u otras } \\
\text { Utiliza lenguaje simbólico numérico para } \\
\text { expresarse }\end{array}$} \\
\hline & & \\
\hline & & \\
\hline & & \\
\hline & & \\
\hline \multirow{10}{*}{$\begin{array}{l}\text { Haciendo matemáticas } \\
\text { (alta demanda cognitiva) }\end{array}$} & \multirow{3}{*}{$\begin{array}{l}\text { 6. Lee y luego explica: } \\
\text { Arístides y Julia han repartido } 14 \text { gaseosas a dos } \\
\text { grupos de religiosos en un concierto: cristianos y } \\
\text { católicos. Pero al repartir las gaseosas, se dieron } \\
\text { cuenta de que no asistió un cristiano. Entonces las } \\
\text { repartieron de este modo: }\end{array}$} & \multirow{10}{*}{$\begin{array}{l}\text { Realiza inferencias } \\
\text { Establece relaciones de información numérica y } \\
\text { gráfico simbólica } \\
\text { Utiliza lenguaje verbal o escrito para comunicar } \\
\text { información nueva } \\
\text { Explica procesos de resolución } \\
\text { Plantea nuevas posiciones problemáticas** }\end{array}$} \\
\hline & & \\
\hline & & \\
\hline & Cristianos $=¥ ¥ ¥ ¥ ¥ ¥ ¥$ gaseosas. & \\
\hline & Católicos $=¥ ¥ ¥ ¥ ¥ ¥ ¥$ gaseosas. & \\
\hline & Entonces... & \\
\hline & ¿ ¿Qué hicieron Arístides y Julia? & \\
\hline & $\begin{array}{l}\text { ¿Cómo se hubieran repartido las gaseosas } \\
\text { entre cristianos y católicos, si todos hubieran } \\
\text { asistido? }\end{array}$ & \\
\hline & $\begin{array}{l}\text { ¿Por qué Arístides y Julia habrán repartido las } \\
\text { gaseosas del modo como se muestra en la figura? }\end{array}$ & \\
\hline & ¿Qué otro problema plantearías a tu modo? & \\
\hline
\end{tabular}

*(Solo se ejemplifican algunos ítems respecto al instrumento); **(desempeño planteado como parte de la investigación).

Nota: Elaboración propia. 
http://doi.org/10.15359/ree.24-3.9

Se exploró en la confiabilidad del instrumento mediante un plan piloto aplicado a 50 estudiantes de segundo grado de otras instituciones aledañas a las del estudio para discriminación de ítems. Esto, con la finalidad de evitar la invalidación externa respecto a la inclusión de sujetos participantes en el experimento. La confiabilidad se consideró mediante el análisis de los datos del plan piloto, mediante el cual se calculó el índice alfa de Cronbach. El resultado se consideró como aceptable $(\alpha=7,89)$.

\section{Procedimiento y recojo de datos}

Las tareas matemáticas se concibieron como actividades que generan determinado nivel motivacional-atencional en el alumnado, y exigen una solución específica, el uso de conocimientos previos como condición necesaria para el aprendizaje. Estos conocimientos obedecen al tipo de tareas conectivas, es decir, exigen la habilidad para la construcción de información (constructivos), y los que no implican dicha construcción (memorísticos). Ante esta necesidad, se recurrió a la teoría de experiencia óptima adaptada al abordaje de tareas cognitivas complejas (Figura 2), con el propósito de elaborar un programa de provocación de desafíos con andamiajes -apoyo- entre docente y sus estudiantes.

Figura 2: Modelo teórico funcional del abordaje mediante provocación por desafíos*

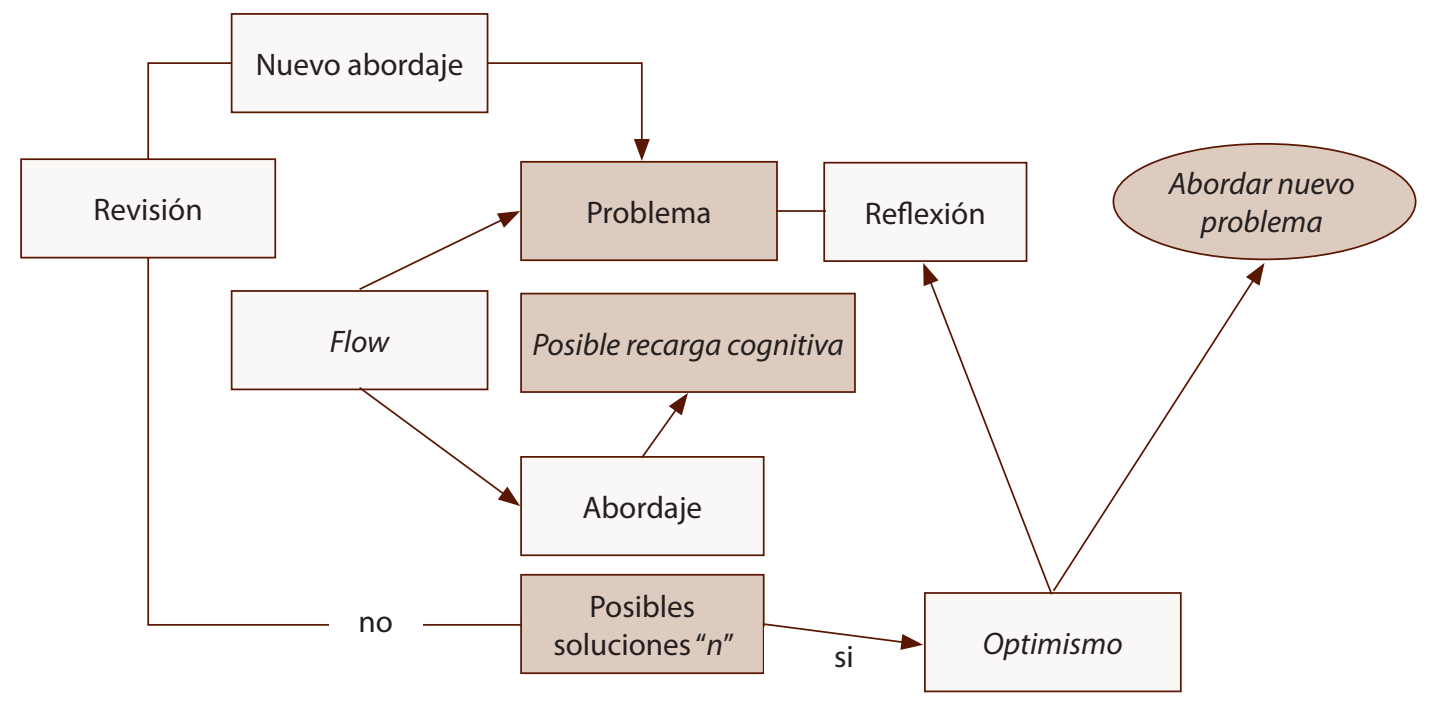

*El estudiantado aborda la recarga cognitiva de modo controlado ante las distintas posibilidades de solución de un problema (n). Si logra realizarlas, desarrollarlas, entonces se está provocando Flow mediante el desafío que le propone su docente en dicho abordaje del problema, este apoyo de control óptimo de la situación permite que el grupo de estudiantes se independice paulatinamente mediante distintos procesos reflexivos que despiertan el optimismo para abordar tareas complejas posteriores.

Nota: Elaboración propia. 
http://doi.org/10.15359/ree.24-3.9

http://www.una.ac.cr/educare

educare@una.ac.cr

Para comprobar la hipótesis inicial, se desarrolló un programa: Propuesta de andamiaje profesorado-alumnado, conformado por 35 sesiones de aprendizaje de 30 minutos acorde al plan curricular de escolaridad básica: propuesta basada en desafíos para el abordaje de tareas de alta demanda cognitiva (Figura 3). Esto se realizó con la finalidad de desarrollar actividades por camuflaje en las actividades cotidianas y curriculares, y evitar la influencia de otras variables internas. Se desarrolló durante seis meses de escolaridad en diversas instituciones educativas en el Perú.

Figura 3: Propuesta de Andamiaje profesor-alumno en la provocación por desafíos*

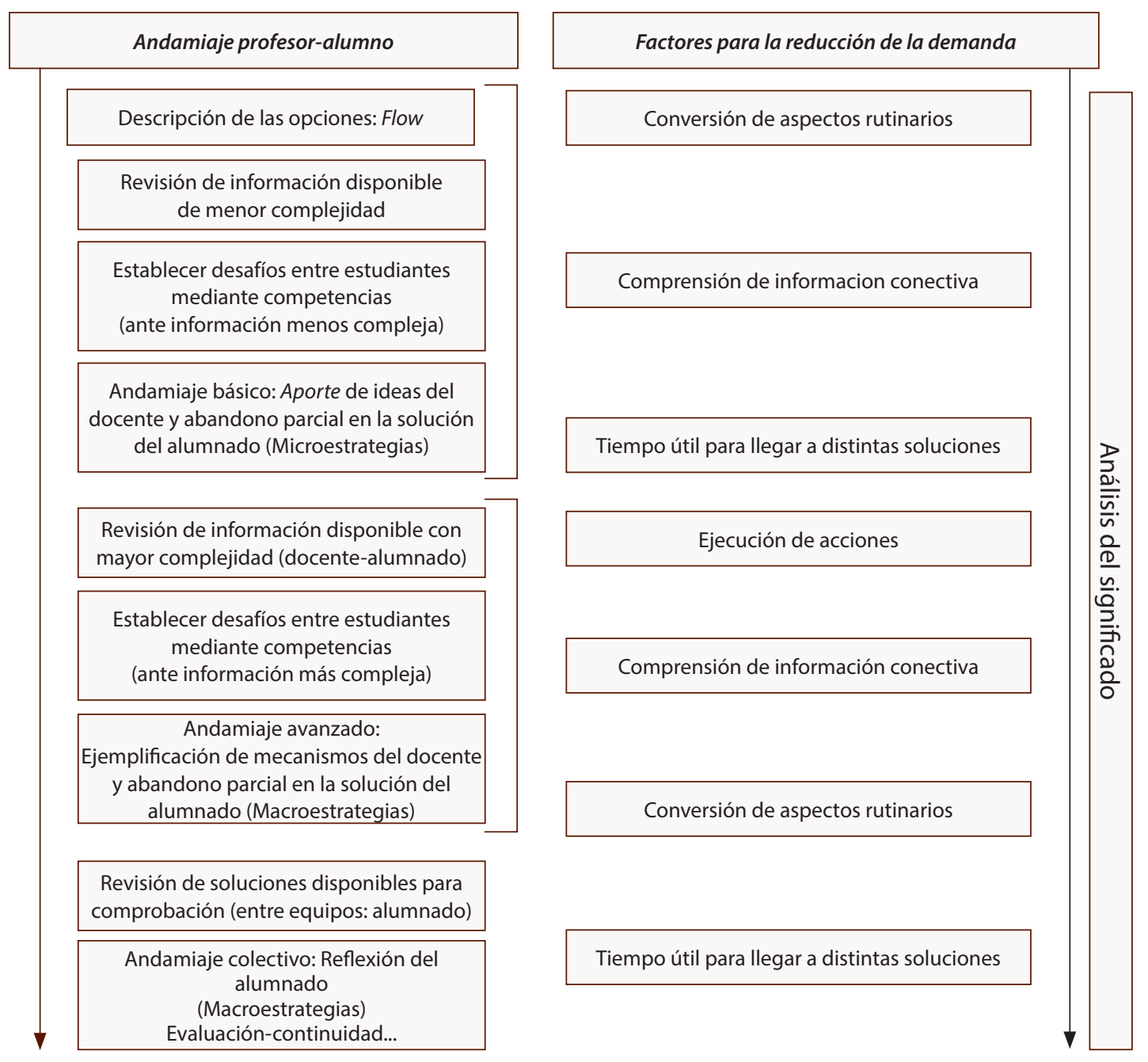

* Propuesta para el abordaje de tareas de alta demanda cognitiva, en correspondencia a los factores asociados para la reducción de la demanda cognitiva de Stein et al. (2009). Microestrategias: Estrategias de lectura y organización; Macroestrategias: Inferencias lógicas, aplicación de recursos de análisis profundizado, análisis de información numérica; preguntas reflexivas, cuestionamiento de saberes previos; entre otros.

Nota: Elaboración propia. 
http://doi.org/10.15359/ree.24-3.9

Una vez elaboradas las sesiones de aprendizaje, se establecieron las fechas para aplicar las sesiones de Andamiaje profesorado-alumnado. Es necesario acotar que los sujetos participantes trabajaron de forma grupal en algunas actividades, con el fin de adaptar su rendimiento en competencias desafiantes durante el proceso de resolución de algunas tareas cognitivas. Sin embargo, para llegar a hacer más preciso este procedimiento fue necesario someter el instrumento de medición (Prueba de problemas aritméticos con demanda cognitiva múltiple [PRODECM]) a corroboración estadística de los ítems inicialmente propuestos en el instrumento original, ya que las tareas cognitivas cumplían un objetivo grupal, pero también necesitaban compararse y clasificarse de manera acorde con su complejidad. Se procedió a un análisis correlacional previo de los 16 ítems planteados inicialmente a través de una medición piloto para clasificación y composición de la prueba de problemas aritméticos con demanda cognitiva múltiple (PRODECM).

Tabla 2: Promedios de categorías y correlacionales de ítems en el análisis de clasificación de las tareas

\begin{tabular}{|c|c|c|c|c|c|c|c|}
\hline Categorías de tareas & Media** & & & $\mathrm{n}^{\circ} \mathrm{de}$ & $m(r)$ & & \\
\hline (baja demanda cognitiva) & 2.45 & $1(7,31)^{*}$ & $2(7,31)^{*}$ & $3(8,79)^{*}$ & & & \\
\hline $\begin{array}{l}\text { Procedimentales no conectivas } \\
\text { (baja demanda cognitiva) }\end{array}$ & 4.47 & $1(-1,01)$ & $2(7,21)^{*}$ & $3(7,43)^{*}$ & $4(8,05)^{*}$ & $5(7,56)^{*}$ & $6(8,45)^{*}$ \\
\hline $\begin{array}{l}\text { Procedimentales conectivas } \\
\text { (alta demanda cognitiva) }\end{array}$ & 2.78 & $1(7,89)^{*}$ & $2(7,56)^{*}$ & $3(1,23)$ & & & \\
\hline $\begin{array}{l}\text { Haciendo matemáticas } \\
\text { (alta demanda cognitiva) }\end{array}$ & 3.78 & $1(3,34)$ & $2(8,75)^{*}$ & $3(8,91)^{*}$ & $4(4,01)$ & & \\
\hline
\end{tabular}

${ }^{*} p<.001 ;{ }^{* *} \mathrm{n}=75$ estudiantes.

Nota: Elaboración propia con base a los datos del estudio.

De los 16 ítems iniciales solo se consideraron 11, cuyas puntuaciones promedio se correlacionaron con las categorías de complejidad propuestas: Tareas de memorización (baja demanda cognitiva), tareas procedimentales no conectivas (baja demanda cognitiva), tareas procedimentales conectivas (alta demanda cognitiva); y haciendo matemáticas (alta demanda cognitiva). El resto de ítems no presentaron correlaciones significativas (Tabla 2), los 11 ítems, clasificados en sus categorías correspondientes, conformaron la versión final del instrumento.

El programa Andamiaje profesorado-alumnado se basó en la teoría de Flow o fluencia, establecido por Csikszentmihalyi (1998a, b; y M. Csikszentmihalyi e I. S. Csikszentmihalyi (1998), mediantelacual se buscó establecer mecanismos deacción traducidosen estímulos motivacionales en la matemática escolar. Los mecanismos se esquematizaron en 50 sesiones de aprendizaje del programa académico de acompañamiento, las cuales se aplicaron durante 6 meses en un año 
http://doi.org/10.15359/ree.24-3.9

http://www.una.ac.cr/educare

educare@una.ac.cr

lectivo. Estas permitieron plantear tres tipos de andamiaje: a) básico, b) avanzado, c) colectivo (figura 4). Mediante este tipo de andamiajes, se estableció el ejercicio de una triada pedagógica: acompañamiento (básico) -apoyo (avanzado)- abandono (colectivo), acorde a cada tipo de andamiaje. El objetivo del programa fue aportarla experiencia del personal docenteconactividades placebo a cada formato, modalidad o técnica de resolución que el estudiantado realizaba. Una cantidad de sesiones de aprendizajes se dirigieron a impulsar el andamiaje de acompañamiento (tipo básico), en este caso, cada docente brindaba actividades basadas en desafíos o retos de cumplimiento de metas a cada subgrupo estudiantil (Tabla 3). El servicio de acompañamiento brindado aquí permitió que el personal docente brindase estrategias al estudiantado, según la dificultad de las tareas que abordaba. En cuanto a las sesiones correspondientes al andamiaje de apoyo (tipo avanzado), la interacción entre docentes y los grupos estudiantiles era mayor, se realizaban resoluciones modelo, ejemplificaciones y otras acciones a imitar por parte del estudiantado, lo cual luego se comprobaría mediante retos aunados a la experiencia previa.

Tabla 3: Mecanismos de acción, naturaleza, métodos pedagógicos, cantidad de sesiones y tareas del programa académico de acompañamiento Andamiaje profesorado-alumnado

\begin{tabular}{|c|c|c|c|c|c|c|c|}
\hline \multirow[t]{2}{*}{$\begin{array}{l}\text { Mecanismo de acción } \\
\text { (tipo de andamiaje) }\end{array}$} & \multirow[t]{2}{*}{ Naturaleza } & \multirow[t]{2}{*}{ Métodos pedagógicos } & \multirow[t]{2}{*}{$\begin{array}{c}\text { Cantidad } \\
\text { de sesiones }\end{array}$} & \multicolumn{4}{|c|}{$\begin{array}{l}\text { Tareas con demanda } \\
\text { cognitiva aplicadas* }\end{array}$} \\
\hline & & & & M & SC & $\mathrm{C}$ & $\mathrm{HM}$ \\
\hline $\begin{array}{l}\text { Acompañamiento } \\
\text { (básico) }\end{array}$ & $\begin{array}{l}\text { Impulsar aprendizajes } \\
\text { mediante metas planteadas }\end{array}$ & $\begin{array}{l}\text { Dinámicas lúdicas } \\
\text { Desafíos por parejas }\end{array}$ & 15 & 4 & 2 & 1 & 1 \\
\hline $\begin{array}{l}\text { Apoyo } \\
\text { (avanzado) }\end{array}$ & $\begin{array}{l}\text { Estímulo de los } \\
\text { aprendizaje mediante } \\
\text { interacciones continuas }\end{array}$ & $\begin{array}{l}\text { Desafíos colectivos } \\
\text { Dinámicas de organización } \\
\text { Actividades de cuestionamiento } \\
\text { colectivo }\end{array}$ & 20 & 2 & 2 & 2 & 2 \\
\hline $\begin{array}{l}\text { Abandono } \\
\text { (colectivo) }\end{array}$ & $\begin{array}{l}\text { Planteamiento de retos } \\
\text { sin acompañamiento } \\
\text { docente }\end{array}$ & $\begin{array}{l}\text { Dinámicas lúdicas } \\
\text { Desafíos colectivos } \\
\text { Planteamiento de metas por } \\
\text { niveles de dificultad }\end{array}$ & 15 & 0 & 2 & 2 & 5 \\
\hline
\end{tabular}

*(por sesión de aprendizaje); total de sesiones de aprendizaje $=50$.

Nota: Elaboración propia.

Por último, el andamiaje de tipo abandono (tipo colectivo) fue denominado así con el fin de establecer menos conexiones entre personal docente y los equipos de trabajo. Solo se brindaban retos individualizados, con el fin de proponer al estudiantado que podría apoyarse con otros compañeros o compañeras por afinidad académica o actitudinal. Por tanto, el seguimiento del personal docente se ejecutaba solo a razón de las soluciones que brindaba el estudiantado en el desarrollo de los retos matemáticos por cada tarea planteada. 
http://doi.org/10.15359/ree.24-3.9

Para la comparación de los datos, se decidió recogerlos mediante la metodología de investigación preexperimental. Se evaluó la demanda cognitiva matemática dos semanas antes del inicio del programa Andamiaje profesorado-alumnado mediante la aplicación del instrumento PRODECM (medición pretest). Luego de dos semanas se aplicó este instrumento en el grupo único, con el fin de obtener los datos de la medición postest.

\section{Análisis de información}

La información se analizó tomando como criterios dos dimensiones del estudio: a) tipo de diseño del experimento, b) tipo de distribución de datos. En el primer caso, al haberse realizado la metodología preexperimental, se optó por el análisis de datos por pruebas no paramétricas de comparación. Sin embargo, como medio de constatación, se recurrió al análisis de normalidad de los datos obtenidos en los momentos pretest y postest del estudio (dimensión b). Se aplicó la prueba Kolmogorov-Smirnov ( $>50$ casos), de cuyos resultados se obtuvo distribución desajustada a la curva de normalidad, tanto en el caso de la variable $(p>.005)$ como en el de las dimensiones $(p<.005)$. Aunque esto indicaba optar por una prueba no paramétrica (signos de Wilcoxon), se optó por aplicar una prueba paramétrica estándar como medida de corroboración en cada caso (t-Student para muestras relacionadas).

\section{Resultados y discusión}

\section{Tareas con baja demanda cognitiva}

En cuanto a tareas de memorización, estudiantes de segundo grado (7 a 8 años de edad) aprendieron a desarrollarlas efectivamente desde el segundo mes, lo cual reflejó diferencias más pronunciadas que en otros meses (primer mes= 1.25; segundo mes=2.35). Los grupos participantes finalizaron el programa Andamiaje profesorado-alumnado, con nivel de promedio muy alto $(m .=2.82)$. A su vez, el cambio fue notorio en la comparación de las mediciones pretest y postest, ya que fueron significativas en pruebas no paramétricas con medianas diferenciadas $\left(M d n_{\text {(pretest) }}=3.45 / M d n_{\text {(postest) }}=4.56\right)$ con rangos estadísticos significativos $\left(\mathrm{W}_{(+)}=72 ; p<.001\right)$. Esta diferencia también se obtuvo en la prueba t-Student $\left(\mathrm{t}_{(1,56)}=1.25 ; \mathrm{gl}_{(75)}=, 000\right)$.

Esto quiere decir que el uso de la información del retén matemático influyó en el desarrollo de las tareas de memorización, por esto las evidencias en significancias fueron obtenidas con probabilidades de confianza del 95\%. Ello revela las condiciones que se desarrollan en tareas de baja demanda cognitiva cuando se estimulan los procesos (Baroody, 2000; Godino et al., 2004; Stein et al., 2009). La facilidad y rapidez de progreso que el programa Andamiaje profesoradoalumnado estableció en el grupo de experimentación se sustentan en este tipo de tareas memorísticas, debido a que en su estructura matemática se calculan dígitos por modalidades 
http://doi.org/10.15359/ree.24-3.9

http://www.una.ac.cr/educare

educare@una.ac.cr

de cálculo entrenado, mental y hasta por el sentido mecánico de realizar operaciones matemáticas. En este caso, el estudiantado peruano logró mayor fluidez en el proceso debido a que en sus escuelas podrían desarrollarse actividades muy similares. Al respecto, se deduce, en correspondencia a los resultados de Ni et al. $(2014,2018)$, que la asociación de conceptos son innecesarios para las tareas memorísticas y es exigente en tareas con alto nivel de complejidad.

La falta de fluidez en la operatividad de procesos matemáticos básicos aletarga otros de mayor dificultad en el estudiantado, y en los cuales la ansiedad es un distractor emergente en el rendimiento (Csikszentmihalyi, 1998a; 1998b; Nakamura, 1998). Antes de iniciar el programa experimental, el estudiantado desarrollaba las tareas básicas con errores en la redacción de dígitos. Por ejemplo, al buscar completar $20+2=\ldots$ lo hacían completando $20+2=2 \ldots$ En cambio, al finalizar el programa (evaluación postest), los aciertos evidenciaron la obtención de mayor determinación y confianza en el desarrollo de este tipo de operaciones (Figura 4, imagen a).

Figura 4: Ejemplificación de tareas de memorización (a) y tareas sin conexiones (b)

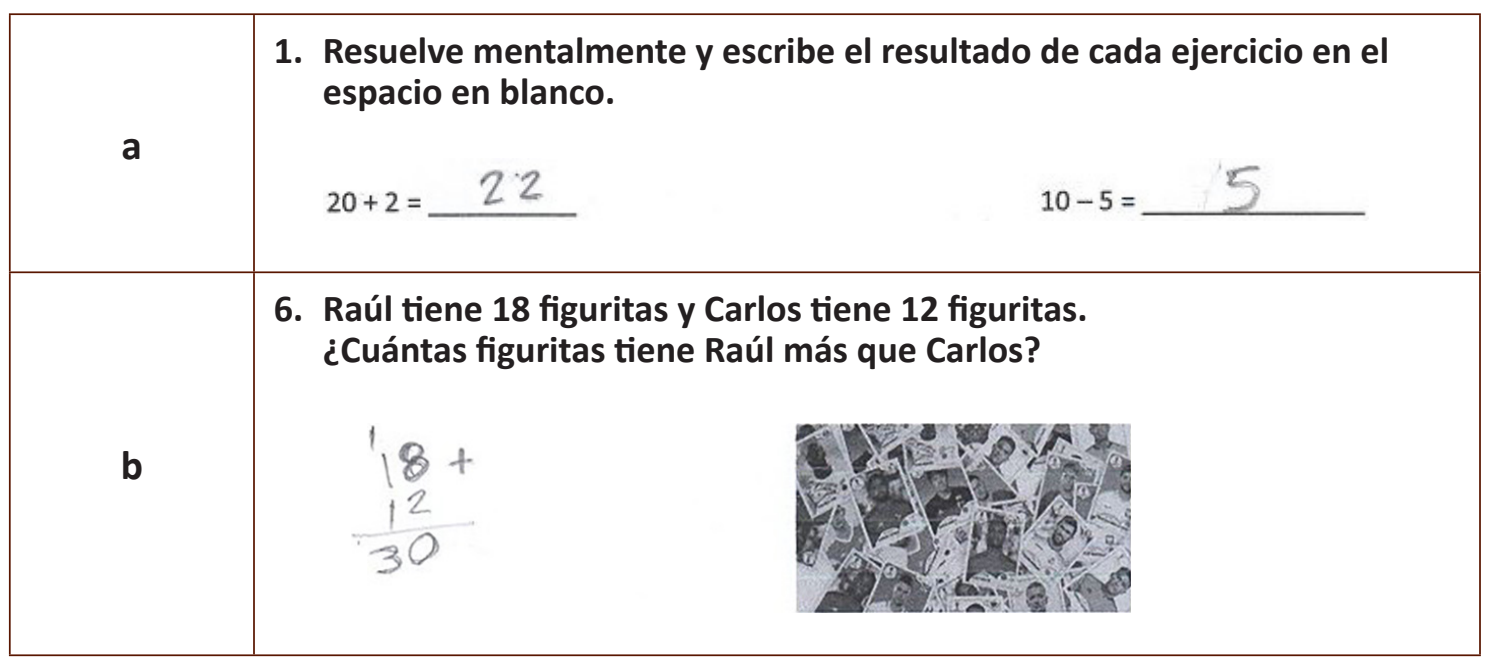

Nota: Elaboración propia con base en la bitácora de investigación.

Estas tareas de baja demanda cognitiva (memorización) resultan menos exigentes, pues implican poca demanda de comprensión y relación de información, lo cual se ha evidenciado en la presente investigación como también en otros estudios similares que rescatan el poder analítico del estudiantado ante cualquier tarea repetitiva, memorística o verticalista (Ayllón et al., 2016; Burgos et al., 2017; Defaz, 2017; Scattarética Muñoz, 2017). Sin embargo, se han encontrado evidencias de que la optimización de las tareas básicas genera mucha confianza e interés en otras tareas más complejas (Hong, 2017; Wu y Lin, 2017). 
http://doi.org/10.15359/ree.24-3.9

En las tareas procedimentales no conectivas (NC), se obtuvo el aumento en su rendimiento entre el tercer y sexto mes de desarrollo del programa (Figura 4). La comparación de las mediciones pretest $\left(M d n_{\text {(pretest) }}=1.67\right)$ y postest $\left(M d n_{\text {(postest) }}=3.93\right)$ presentaron diferencias desde la perspectiva estadística no paramétrica $\left(\mathrm{W}_{(+)}=69 ; p<.001\right)$, como también se evidenciaron puntuaciones significativas en la estadística paramétrica $\left(\mathrm{t}_{(3,97)}=4.45 ; \mathrm{gl}_{(74)}=, 000\right)$, lo que representa la existencia de la mejora entre ambos puntos de contraste (pre y postest).

Este contraste ha determinado la existencia de diferencias en el momento inicial del desarrollo del programa Andamiaje profesorado-alumnado en cuanto a los promedios obtenidos. Esto indicó que el estudiantado desarrolló menores niveles de rechazo a las tareas complejas. Logró incrementar su autodeterminación ante las actividades como lo sugieren estudios con propuestas y resultados similares (Ersöz y Eklund, 2017; Yeh y Lin, 2018). Esto se ha identificado a través del análisis de respuestas en la medición pretest, entre las cuales se encontraron respuestas brindadas a problemas tipo en los cuales el estudiantado generaba erratas al realizar operaciones o simplemente evadían su realización. En el caso de operaciones directas, algunos sujetos erraban en la operación a realizar (Figura 4, gráfico b). En la valoración de los datos postest se evidenció el cambio hacia la resolución de este tipo de tareas, por lo que se dedujo que las actividades (dinámicas, retos y desafíos hacia la meta) permitieron desarrollar mayor concentración hacia la tarea y la búsqueda de soluciones continua en ensayo y error.

Aquí es importante hacer notar que las tareas de memorización fueron similares en operaciones matemáticas, pero también se presentaron dos tareas sobre resolución de problemas de menor complejidad que otras, con estructura semántica adecuada para el objetivo del programa. Es decir, se hicieron equivalentes que consideraban el peso estructural de los problemas con la capacidad de comprensión del estudiantado, lo cual guarda similitud con lo que otras investigaciones evidenciaron sobre el control de estructuras semánticas y la información inferencial analizada (Benedicto et al., 2015; Scattarética Muñoz, 2017; Stein et al., 2009; Yeh y Lin, 2018).

\section{Tareas con alta demanda cognitiva}

En cuanto a la comparación descriptiva entre las tareas Procedimentales Conectivas (PC) y Haciendo Matemáticas (HM) (Figura 5), el aumento ha sido más potencial en las PC que en las HM. La diferencia es notable a partir del tercer mes de aplicación del programa, y parece estandarizarse entre el quinto y sexto mes, aunque las diferencias en el sexto mes son mínimas $(P C=1.55 ; H M=1.56)$, esto pone de relevancia que las tareas Haciendo Matemáticas, ostentaron procedimientos que implicaban mayores niveles de relación de información, pero a su vez, más exigentes en cuanto a su comprobación y reflexión. Por esto, el estudiantado procedió a utilizar conceptos para establecer relaciones entre sí, como también, con otros conceptos 
http://doi.org/10.15359/ree.24-3.9

http://www.una.ac.cr/educare

educare@una.ac.cr

al utilizar habilidades más específicas: representar la información, plantear soluciones, escrutar información implícita y relacionarla. En suma, se ha observado que en la ejecución de estas capacidades el alumnado implementa micro estrategias como segunda opción ante el abordaje y resolución de problemas complejos, a pesar de la complejidad del ejercicio o la constitución semántica de los problemas, lo cual afectaría en el logro del rendimiento efectivo como lo descubrieron en otras investigaciones que han trabajado en la autorregulación como acompañante cognitivo o estrategia de auto supervisión (Canet-Juric et al., 2016; Ersöz y Eklund, 2017; Yeh y Lin, 2018).

Figura 5: Descripción de promedios en tareas de demanda cognitiva Procedimentales No Conectivas, Procedimentales Conectivas y Haciendo Matemáticas*

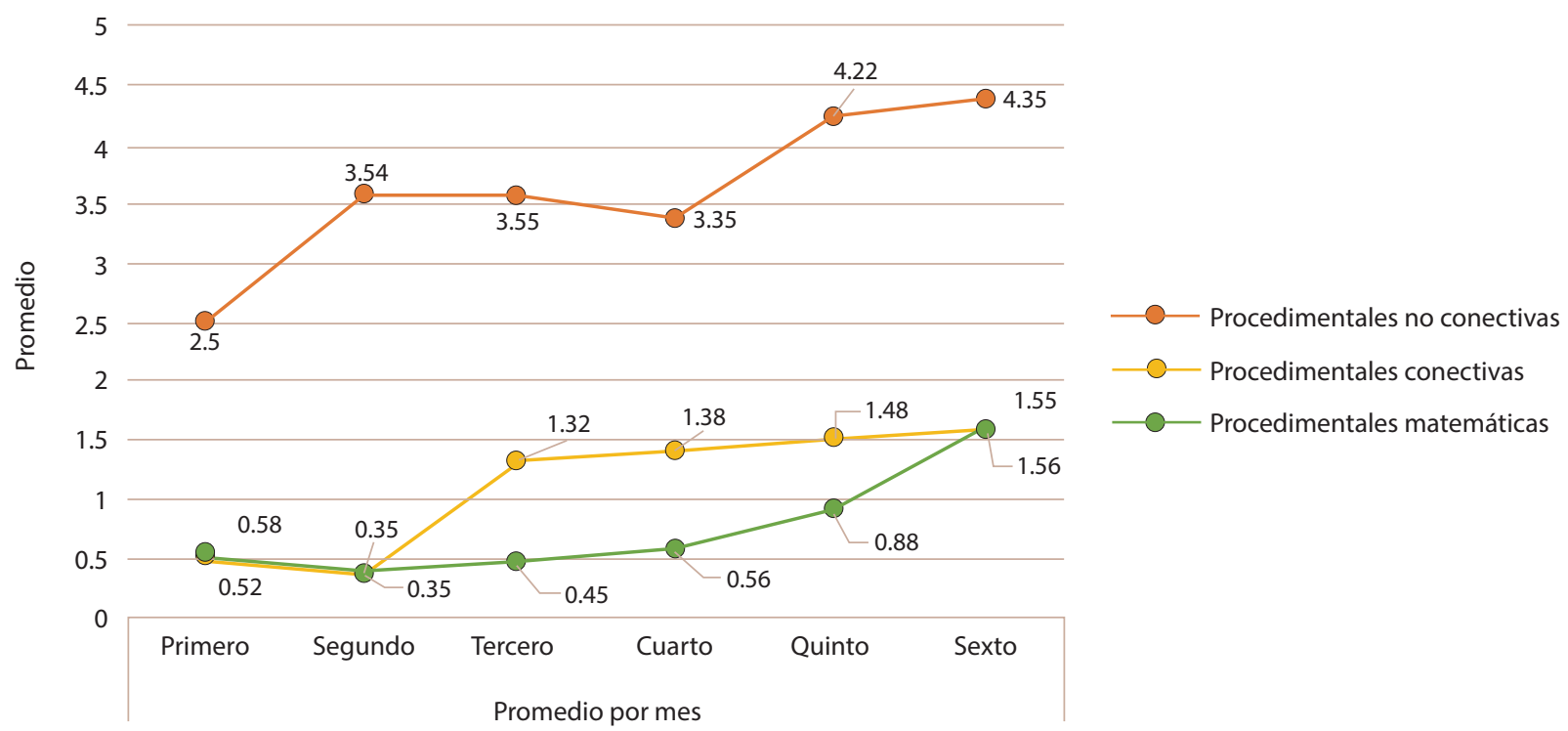

* Representación estadística en los seis meses de experimentación durante el programa Andamiaje profesor-alumno con provocación por desafíos cognitivos.

Nota: Elaboración propia con base en los datos del estudio.

En definitiva, el alumnado logró dichas habilidades, de los cuales se deduce la aparición de procesos reguladores de ansiedad / tedio ante el abordaje de tareas de alta demanda, aunque el progreso fue lento, de todos modos se vivenció entre el quinto y sexto mes de experimentación. 
http://doi.org/10.15359/ree.24-3.9

http://www.una.ac.cr/educare educare@una.ac.cr

Figura 6: Ejemplificación de tareas conectivas (a) y tareas hacer matemáticas (b) luego de aplicar el programa Andamiaje profesor alumno

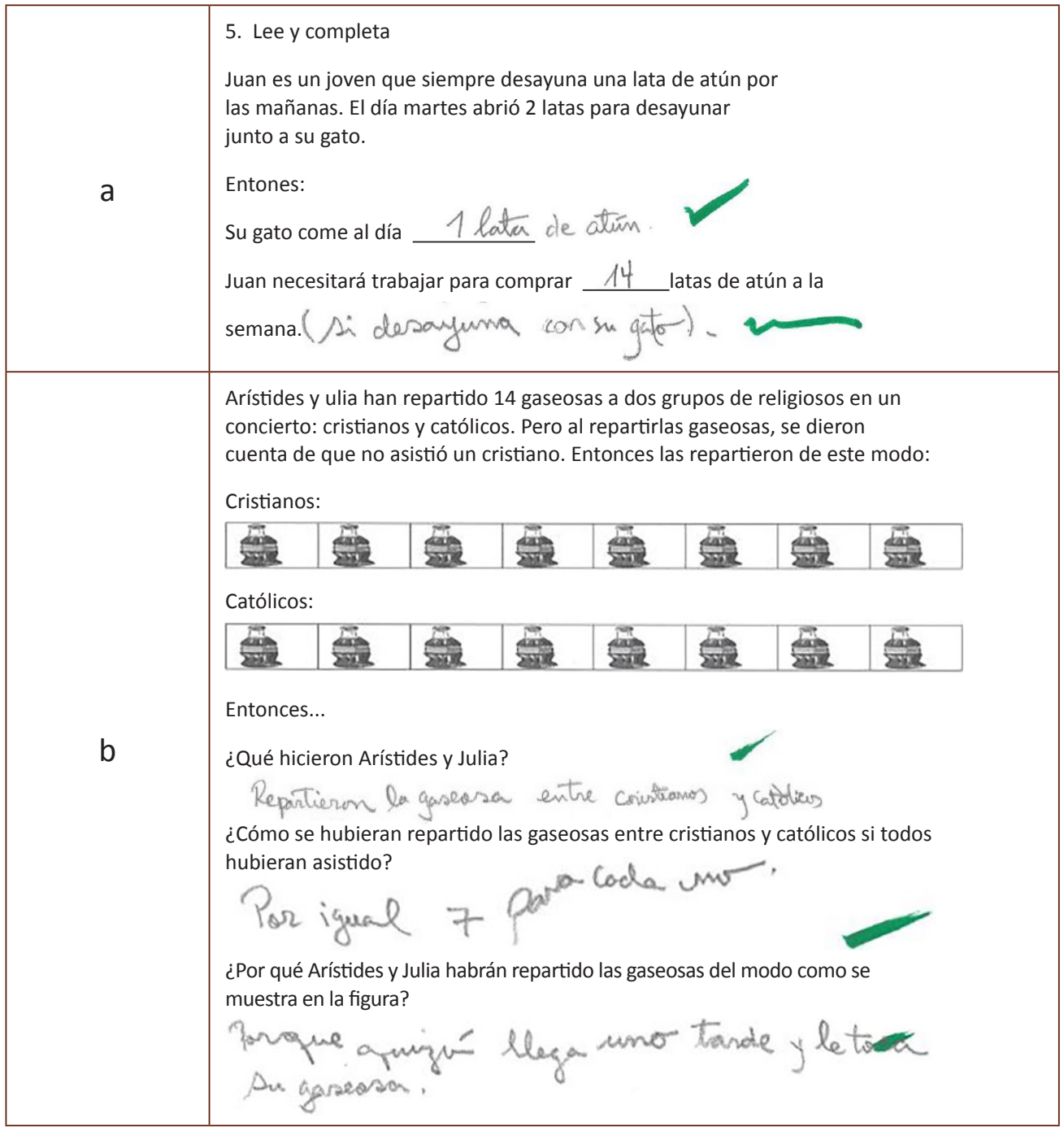

Nota: Elaboración propia en base a la bitácora de investigación.

Las medianas relativas a las puntuaciones de la dimensión tareas Procedimentales Conectivas $(\mathrm{PC})$, reportaron diferencias en las comparaciones pretest ( $M d n=2.24$ ) y postest $(M d n=4.56)$, las cuales también se comprobaron en la prueba estadística $\left(\mathrm{W}_{(+)}=71 ;\right.$ sig. $=, 000$; $p<.001)$. Estas diferencias también se corroboraron en pruebas paramétricas $\left(\mathrm{t}{ }_{(1,24)}=1.76 ; \mathrm{gl}\right.$ (71) $=, 001 ; p<.005)$. Aquí el resultado fue peculiar: las diferencias más notorias se obtuvieron al obtener significancias menores a $5 \%$ en la prueba paramétrica. En cuanto al análisis de 
http://doi.org/10.15359/ree.24-3.9

http://www.una.ac.cr/educare

educare@una.ac.cr

resultados, en el indicador capacidad de hallar soluciones correctas a operaciones propuestas en tareas conectivas, se encontraron deficiencias u omisiones en el desarrollo de operaciones complejas antes de iniciar el programa de experimentación (medición pretest). Estas implicaban habilidades de comprensión de información implícita y habilidades de relación. Lo importante aquí fue notar entre los resultados de medición postest, que el estudiantado lograba hacer alguna comprensión inter informacional para obtener datos que naturalmente solo obtenían en tareas memorísticas (Figura 6, imagen a).

Un ejemplo claro fue evidenciar que realiza la deducción "1 lata de atún", lo cual implicó tres acciones: a) extracción del significado implícito, b) asociación a conceptos abstractos (numéricos), c) operación mental, y, d) comunicación matemática (Figura 8, gráfico a). En ese ejemplo, es notable la forma en que el estudiantado, muy aparte de obtener la respuesta numérica "14", también declaró:"... si desayuna con su gato", de cuya proposición se deduce que esta tarea conectiva permite que elestudiantado poco a poco vayan asegurando sus respuestas, lógicas y meta cognitivas a su vez. Muchas de las actividades del programa Andamiaje profesoralumno (Tabla 3) de tipo abandono: Dinámicas lúdicas, desafíos colectivos, planteamiento de metas por niveles de dificultad; permitieron desarrollar aspectos reguladores y meta cognitivos que se pensaban propios de las tareas hacer matemáticas. Estos resultados son semejantes a otros en que el aseguramiento y la meta comprensión de consignas son importantes en el abordaje de tareas con alta demanda cognitiva (Benedicto et al., 2015; Burgos et al., 2017; Stein et al., 2009). En esa situación, la capacidad para elaborar múltiples soluciones y comprobarlas es más difícil en estudiantes que solo buscan respuestas correctas a las preguntas que abordan, 0 aquellos que tienen por objetivo "no errar" en el desarrollo del ejercicio.

En razón a las tareas Haciendo Matemáticas (HM), las diferencias en medidas no paramétricas establecieron diferencias significativas descriptivas ( $M d n_{\text {(pretest) }}=1.51 / M d n_{\text {(postest) }}$ = 2.33), como también a nivel estadístico inferencial $\left(\mathrm{W}_{(+)}=68 ; \mathrm{W}_{(-)}=2 ; \mathrm{W}_{(\mathrm{e})}=6 ;\right.$ sig. $=, 004 ; p$ $<.005)$. En las medidas paramétricas estas diferencias fueron significativas $\left(\mathrm{t}_{(2,05)}=1.02 ; \mathrm{gl}{ }_{(71)}=\right.$ $, 001 ; p<.005)$, lo cual demostró que el programa fue influyente en el logro de las habilidades del estudiantado para obtener resultados más eficaces con lo que los problemas solicitaban. De forma particular, el rigor de las tareas HM presentó mayor dificultad durante cuatro meses, lo cual significa que el estudiantado tuvo poca oportunidad para realizar una comprensión relacional en potencia ya que resultó ser más compleja, de lo cual puede colegirse que las bondades del programa también elevaron el optimismo y satisfacción por realizar este tipo de tareas (Hong, 2017; Makvandi et al., 2018; Sedigh Srouni et al., 2016). El éxito ante los desafíos conllevó a que el estudiantado ensayara muchas veces este tipo de tareas hasta lograr mejores resultados como lo planteaban referencias teóricas sobre este tipo de tareas en las que también se realizan procesos conectivos o relacionales de información en la comprensión de la tarea (M. Csikszentmihalyi e I. S. Csikszentmihalyi, 1998; Nakamura, 1998), para asegurar procedimientos operativos, verificar resultados a priori, y emitir nuevas formas de solución. 
http://doi.org/10.15359/ree.24-3.9

En las evidencias referentes a este estudio, el estudiantado adoptó nuevas habilidades con respecto de aquellas que en el inicio eran deficientes, y por las cuales las tareas de hacer matemática eran complejas de resolver. En muchos casos, el estudiantado obvió las consignas de cada tarea y orientaron su resolución hacia la resolución de operaciones. En cambio, en la evaluación postest (Figura 6, gráfico b), los registros evidenciaron inferencias notables ante consignas que implicaban el uso de información relacionada y el análisis de la comprobación de información implícita. Es importante notar que, el estudiantado lograba realizar explicaciones que implicaban otras capacidades asociadas al razonamiento, la aplicación de predicciones lógicas; y la reflexión ante situaciones matemáticas, tal como lo expresa la respuesta de la figura 8 a la pregunta: ¿Por qué Arístides y Julia habrán repartido las gaseosas del modo como se muestra en la figura? Respuesta: "Porque quizá llega uno tarde y le toca su gaseosa...".

El estudiantado también lograró crear nuevas situaciones matemáticas, relacionando la información a su experiencia vivida. Por ejemplo, en una de las preguntas que se formuló al problema del gráfico b (Figura 6): ¿Qué otro problema plantearías a tu modo?, el estudiante contesta: "¿qué pasa si le roban dos gaseosas a los cristianos y 5 a los católicos?". Ante estas evidencias se puede asumir que, al comprobarse la hipótesis planteada en un inicio, la provocación por desafíos basados en la teoría de experiencia óptima (Flow) sí permitió que el estudiantado abordara tareas de alta demanda cognitiva de forma paulatina, o más bien dicho, de forma procesual. Claro está que el desarrollo de este tipo de tareas mediante desafíos estabiliza la práctica matemática, y vuelve al estudiantado má seguros y con interés por comprobar sus resultados de modo constante.

El estudio contribuye en la comprensión del proceso de abordaje del alumnado cuando se encuentra motivado por desafíos ante una tarea compleja; pero, a su vez, dichos retos pueden ser algún factor motivacional hacia el abordaje de dicha actividad. Mucho estudiantado rechaza la iniciativa de sus docentes, y así lo aborden en conjunto, el temor al fracaso lo puede inutilizar en sus actitudes para responder ante la dificultad de las tareas cognitivas. Sin embargo, cuando se provoca el desarrollo de las tareas con determinado nivel de demanda cognitiva, éste debe incrementarse paulatinamente con el fin de establecer estrategias más seguras y reguladas ante situaciones complejas en la matemática. Por último, la progresión que disminuye, como se visualizó en el promedio del segundo mes de abordaje de tareas procedimentales conectivas $(P C=0.35$ ), demarcó que el programa de estímulos (Andamiaje profesorado-alumnado) no incitó al estudiantado a desarrollar lo que no quiere hacer.

\section{Conclusiones}

1. Las tareas matemáticas memorísticas o de memorización, las cuales fueron consideradas de baja demanda cognitiva, fueron significativamente influenciadas por la provocación por desafíos durante los seis meses de estimulación del programa Andamiaje 
http://doi.org/10.15359/ree.24-3.9

http://www.una.ac.cr/educare

educare@una.ac.cr

profesorado-alumnado; sin embargo, el avance fue efectivo desde el segundo mes de aplicación, por lo tanto, el estudiantado realizó procesos cognitivos muy básicos con estímulos estabilizadores de experiencia óptima.

2. Las tareas procedimentales no conectivas (NC) presentaron mejoras significativas luego que se desarrolló el programa Andamiaje profesorado-alumnado durante los seis meses de aplicación con cambios significativos desde el quinto mes, desde el cual se desarrolló la autodeterminación y autoeficacia, las cuales permitieron que los sujetos analizaran estructuras semánticas complejas para el desarrollo de la tarea compleja.

3. Las tareas procedimentales conectivas (PC) se desarrollaron en el alumnado de segundo grado, luego de la provocación por desafíos. Aunque la búsqueda de soluciones, reflexión y comprobación de resultados maduró con lentitud, a su vez, esto demostró que es habitual que dicho alumnado, con mucha más costumbre, desarrollase tareas de baja demanda cognitiva en sus clases diarias.

4. Las tareas de alta demanda cognitiva -haciendo matemáticas (HM) se expandieron de forma significativa en los sujetos implicados en el estudio, lo cual demostró que la provocación por desafíos generó múltiples formas de solución que les sirvió para comprobarlas entre sí y así sentirse más seguros ante las tareas complejas que abordaron en el programa y luego de efectuarlo.

5. Las evidencias obtenidas en este estudio permiten comprender que la esencia del logro de fluencia (Flow) exige establecer puentes o niveles entre el conocimiento de lo que no se puede hacer con lo que sí, por cuanto, es más asequible que el profesorado desarrolle el andamiaje de apoyo; pero más complejo es para el personal docente llegar al siguiente paso, desarrollar la pedagogía basada en el abandono. Este hallazgo necesita profundizarse, con el fin de estudiar, si el logro de la independencia cognitiva en el alumnado emerge acorde con sus posibilidades, sin volver a recurrir al aporte docente ante las dificultades en el abordaje de tareas complejas.

6. La principal limitación se centró en la respuesta del colectivo de estudiantes, sobre todo cuando se agrupan y, en cuyo momento, el docente o la docente debió permitir trabajar de forma agrupada con el estudiantado, ya que en este caso se intentó generar trabajos de tipo personalizado. Es evidente que el logro en tareas de alta demanda fue individual, el poco contacto con el grupo de estudiantes no permitió evaluar el desarrollo de tareas complejas con estudiantes agrupados, en principio, por el hecho de que las diferencias en competencia matemática influenciarían en el promedio total por tarea desarrollada. Esta limitación invita a desarrollar estudios en los que se trabajen estrategias con andamiajes y desafíos colectivos, con el fin de obtener diferencias entre grupos integrados en un aula experimental y así analizar los desempeños cooperativos entre los sujetos participantes. 
http://doi.org/10.15359/ree.24-3.9

http://www.una.ac.cr/educare educare@una.ac.cr

\section{Referencias}

Aguirre-Leguizamo, E. (2016). Flexibilidad cognitiva y atención en aprendices SENA según su desempeño académico [Tesis de maestría]. Universidad Internacional de la Rioja, Colombia. https://reunir.unir.net/handle/123456789/4876

Aubrey, S. (2016). Inter-cultural contact and flow in a task-based Japanese EFL classroom. Language Teaching Research, 21(6), 717-734. https://doi.org/10.1177/1362168816683563

Ayllón, M.F., Gómez, I. A.yBallesta-Claver,J. (2016). Pensamiento matemático y creatividad a través de la invención y resolución de problemas matemáticos. Propósitos y representaciones, 4(1), 169-218. https://doi.org/10.20511/pyr2016.v4n1.89

Balbuena, H. C. (2017, febrero). ¿Cómo elaborar situaciones desafiantes para lograr aprendizajes en nuestros estudiantes? [Archivo en un blog]. http://hugocarlos.com/blog/44-comoelaborar-situaciones-desafiantes-para-lograr-aprendizajes-en-nuestros-estudiante

Baroody, A. J. (2000). El pensamiento matemático de los niños. Un marco evolutivo para maestros de preescolar, ciclo inicial y educación especial. Visor.

Barriteau Phaire, C. (2013). Managing mathematics: How does classroom management affect the maintenance of high cognitive demand tasks during lessons with standards-based instructional materials? (Publicación No. 3567225) [Tesis doctoral, New York University, United States]. ProQuest Dissertations Publishing LLC. https://search.proquest.com/ docview/1417776134

Benedicto, C., Jaime, A., Gutiérrez, Á. (2015). Análisis de la demanda cognitiva de problemas de patrones geométricos. En C. Fernández Verdú, M. Molina González y N. Planas Raig (Eds.), Investigación en educación matemática XIX (pp. 153-162). Universidad de Alicante. http:// rua.ua.es/dspace/handle/10045/51591

Bettencourt, K. (2017). Adolescent risk behavior and experiences with Flow [Tesis de doctorado]. William James College, United States.

Bologna, E. y Urrutia, A. (2011). Comparación entre dos grupos. En E. Bologna (Autor). Estadística para la psicología y educación (pp. 371-400). Brujas. https://www.academia.edu/27629330/ Estadistica Para Psicologia y Educacion 1ed Bologna

Budiarto, M. T., Khabibah, S. y Setianingsih, R. (2017). Construction of high school students' abstraction levels in understanding the concept of quadrilaterals. International Education Studies, 10(2), 148-155. https://doi.org/10.5539/ies.v10n2p148

Butto Zarzar, C. M. y Delgado, J. (2020). Programa de talento matemático con estudiantes de educación básica: Un estudio con los procesos de generalización. Zona Próxima, 32, 1-13. http://rcientificas.uninorte.edu.co/index.php/zona/article/viewArticle/12079 
http://doi.org/10.15359/ree.24-3.9

http://www.una.ac.cr/educare

educare@una.ac.cr

Burgos, M., Giacomone, B., Beltrán-Pelliecer, P. y Godino, J. D. (2017). Reconocimiento de niveles de algebrización en una tarea de proporcionalidad por futuros profesores de matemáticas de secundaria. En J. M. Muñoz Escolano, A. ArnalBailera, P. Beltrán Pellicer, M. L. Callejo de la Vega y J. Carrillo Yáñez (Eds.), Investigación en educación matemática XXI (pp. 177-186). SEIEM. https://dialnet.unirioja.es/servlet/libro?codigo=705555

Campbell, D.T. y Stanley, J.C. (2011). Diseños experimentales y cuasiexperimentales en la investigación social. Amorrortu.

Canet-Juric, L., Introzzi, I., Andrés, M. L. y Stelzer, F. (2016). La contribución de las funciones ejecutivas a la autorregulación. Cuadernos de Neuropsicología, Panamerican Journal of Neuropsychology, 10(2), 106-128. http://www.cnps.cl/index.php/cnps/article/view/238/253

Caviedes-Barreda, S.; de Gamboa-Rojas, G.y Badillo-Jiménez, E. (2019). Conexiones matemáticas que establecen maestros en formación al resolver tareas de medida y comparación de áreas. Praxis, 15(1), 69-87. http://dx.doi.org/10.21676/23897856.2984

Challco, G. C., Andrade, F. R. H., Borges, S. S., Bittencourt, I. I. y Isotani, S. (2016). Toward a unified modeling of learner's growth process and flow theory. Educational Technology \& Society, 19(2), 215-227. https://drive.google.com/file/d/1B1nmLRKLKPrN3pLLulvkwRwvLE6Aw $\underline{\mathrm{LS} 1 / \mathrm{view}}$

Cirino de Jesús, C. (2011). Análise crítica de tarefas matemáticas: um estudo com professores que ensinam matemática nos anos iniciais do ensino fundamental [Tesis de maestría]. Universidad Estatal de Londrina, Londrina, Brasil. http://www.educadores.diaadia.pr.gov. br/modules/mydownloads 01/visit.php?cid=4\&lid=7101

Csikszentmihalyi, M. (2014). Learning, "flow," and happiness. En Applications of Flow in Human Development and Education (pp. 153-172). https://doi.org/10.1007/978-94-017-9094-9 7

Csikszentmihalyi, M. (1998a). Creatividad. El fluir y la psicología del descubrimiento y la invención. Paidós.

Csikszentmihalyi, M. (1998b). Fluir (Flow). Una psicología de la felicidad. Editorial Kairós.

Csikszentmihalyi, M.y Csikszentmihalyi, I.S.(Eds.).(1998). Experienciaóptima. Estudiospsicológicos del flujo en la conciencia. Desclée de Brouwer.

Dávila, K. y Trujillo, E. (2016). Rendimiento de los estudiantes de $6^{\circ}$ grado de primaria en la prueba FAB de resolución de tareas de alta y baja demanda cognitiva referencias a fracciones [Tesis de maestría]. Pontificia Universidad Católica del Perú, Lima, Perú.

Defaz, G. J. (2017). El desarrollo de habilidades cognitivas mediante la resolución de problemas matemáticos. Journal of Science and Research, 2(5), 14-17. https://doi.org/10.26910/ issn.2528-8083vol2iss5.2017pp14-17 
http://doi.org/10.15359/ree.24-3.9

Doyle, W. (1983). Academic work. Review of Educational Research, 53(2), 159-199. https://doi. org/10.3102/00346543053002159

Doyle,W.(1988). Workin mathematics classes:The context of students'thinking during instruction. Educational Psychologists, 23(2), 167-180. https://doi.org/10.1207/s15326985ep2302 6

Ersöz, G. y Eklund, R. C. (2017). Behavioral regulation and dispositional flow in exercise among American College Students relative to stages of change and gender. Journal of American College Health, 65(2), 94-102. https://doi.org/10.1080/07448481.2016.1239203

Garces-Bascal, R. M., Cohen, L. y Tan, L. S. (2011). Soul behind the skill, heart behind the technique: Experiences of flow among artistically talented students in Singapore. Gifted Child Quarterly, 55(3), 194-207. https://doi.org/10.1177/0016986211413574

Georgius, K. (2013). Planning and enacting mathematical tasks of high cognitive demand in the primary classroom (Publicación No. 3618592) [Tesis doctoral]. The University of Nebraska, Lincoln. ProQuest Dissertations Publishing LLC. https://search.proquest.com/ docview/1530478491

Godino, J. D., Batanero, C., Font, V., Cid, E., Ruiz, F. y Roa, R. (2004). Didáctica de la matemática para maestros. GAMI. https://www.ugr.es/ jgodino/edumat-maestros/manual/9 didactica maestros.pdf

González, A. (2013). ¿A resolver problemas se enseña? El problema como contenido a ser enseñado de $1^{\circ}$ a $7^{\circ}$. Homo Sapiens.

Hernández Sampieri, R., Fernández Collado, C. y Baptista Lucio, P. (2014). Metodología de la investigación (6a Ed.). McGraw-Hill.

Holguin-Alvarez, J. A. Villa-Morocho, C., Montalvo-Callirgos, M., Villena-Guerrero, M., CarrascoNúñez, Y. y Espinola-Ayala, L. (2019). Significado del aprendizaje-enseñanza de la matemática en contextos lingüísticos del quechua y citadinos, Investigación Valdizana, 13(3), 143-155. https://doi.org/10.33554/riv.13.3.343

Hong, F.-Y. (2017). Antecedent and consequence of school academic optimism and teachers' academic optimism model. Educational Studies, 43(2), 165-185. https://doi.org/10.1080/0 3055698.2016.1248902

León, J. y Youn, M.-J. (2016). El efecto de los procesos escolares en el rendimiento en matemática y las brechas de rendimiento debido a diferencias socioeconómicas de los estudiantes peruanos. Revista Peruana de Investigación Educativa, 8, 149-180. http://revistas.siep.org. pe/index.php/RPIE/article/view/72/138 
http://doi.org/10.15359/ree.24-3.9

http://www.una.ac.cr/educare

educare@una.ac.cr

Makvandi, A., Naderi, F., Makvandi, B., Pasha, R. y Ehteshamzadeh, P. (2018). Academic optimism and organizational citizenship behaviour amongstsecondary school teachers. International Journal of Emotional Education, 10(1), 164-166. https://www.um.edu.mt/ijee

Mateus Nieves, E. (2015). Configuraciones epistémicas previas para dar significado global al objeto matemático "método de integración por partes". En P. Lestón (Ed.), Acta Latinoamericana de Matemática Educativa, 28, 145-153). Comité Latinaomericano de Matemática Educativa. http://funes.uniandes.edu.co/10718/

McCormick, M. (2016). Exploring the cognitive demand and features of problem solving tasks in primary mathematics classrooms. En B. White, M. Chinnappan y S. Trenholm (Eds.), Opening up mathematics education research (Actas de la 39th conferencia anual del Mathematics Education Research Group of Australasia). MERGBA. https://eric.ed.gov/?q=+tasks+of+hig $\underline{\mathrm{h}+\text { cognitive+demand\&pg=2\&id=ED572329 }}$

Mesurado, B. (2008). Validez factorial y fiabilidad del cuestionario de experiencia óptima (Flow) para niños y adolescentes. Revista Iberoamericana de Diagnóstico y Evaluación - e Avaliação Psicológica, 1(25), 159-178. http://www.redalyc.org/articulo.oa?id=459645445009

Ministerio de Educación, Perú. (2016a). Programa curricular de educación primaria. http://www. minedu.gob.pe/curriculo/

Ministerio de Educación, Perú. (2016b). Resultados de la evaluación censal de estudiantes ECE 2016. http://umc.minedu.gob.pe/resultadosece2016/

Mwadzaangati, L. (2019). Comparison of geometric proof development tasks as set up in the textbook and as implemented by teachers in the classroom. Pythagoras, 40(1), 1-14. https://doi.org/10.4102/pythagoras.v40i1.458

Nakamura, J. (1998). Experiencia óptima y las aplicaciones del talento. En M. Csikszentmihalyi e I. S. Csikszentmihalyi (Eds.), Experiencia óptima. Estudios psicológicos del flujo en la conciencia (pp. 71-90). Desclée de Brouwer.

$\mathrm{Ni}$, Y., Zhou, D., Li, X. y Li, Q. (2014). Relations of instructional tasks to teacher-student discourse in mathematics classrooms of chinese primary schools. Cognition and Instruction, 32(1), 2-43. https://doi.org/10.1080/07370008.2013.857319

Ni, Y., Zhou, D.-H. R., Cai, J., Li, X., Li, Q. y Sun, I. X. (2018). Improving cognitive and affective learning outcomes of students through mathematics instructional tasks of high cognitive demand. Journal of Educational Research, 111(6), 704-719. https://doi.org/10.1080/00220 $\underline{671.2017 .1402748}$

Organización para la Cooperación y el Desarrollo Económico. (2015). PISA 2015: Primeros resultados. http://umc.minedu.gob.pe/resultados-de-evaluacion-pisa-2015/ 
http://doi.org/10.15359/ree.24-3.9

Ponce, L., Preiss, D. y Núñez, M. (2010). Demanda cognitiva en la clase de matemáticas chilena. https://docplayer.es/40897836-Demanda-cognitiva-en-la-clase-de-matematicaschilena.html

Rosillo Juárez, J. (2018). Desarrollo cognitivo y demanda cognitiva [Diapositivas en PowerPoint]. https://danielalmeyda.files.wordpress.com/2018/04/ppt-demanda-cognitiva.pdf

Sanz, P. (2015). El tránsito de la escuela pública a la escuela privada en el sector emergente de Lima Metropolitana: ¿Buscando mejor calidad? Revista Peruana de Investigación Educativa, 7, 95-125. http://revistas.siep.org.pe/index.php/RPIE/article/view/51

Scattarética Muñoz, F. (2017). Caracterización de tareas multiplicativas a partir de la invención de problemas matemáticos [Tesis de licenciatura]. Universidad Catolica del Norte, Antofagasta, Chile. http://funes.uniandes.edu.co/9296/

Sedigh Srouni, A., Jenaabadi, H. y Pourghaz, A. (2016). The relationship of mental pressure with optimism and academic achievement motivation among second grade male high school students. International Education Studies, 9(8), 127-133. https://doi.org/10.5539/ies. v9n8p127

Sosa Moguel, L. E., Aparicio Landa, E. y Cabañas-Sánchez, G. (2020). Fases del razonamiento inductivo que presentan profesores de matemáticas al resolver un problema de generalización, PNA, 14(2), 118-140. http://hdl.handle.net/10481/60196

Stein, M. K., Smith, M. S., Henningsen, M. y Silver, E. (2009). Implementing standards-based mathematics instruction: A Casebook for Professional Development ( $2^{\text {da }}$ ed.). National Academy Press.

Suh, J. y Seshaiyer, P. (2015). Examining teachers' understanding of the mathematical learning progression through vertical articulation during lesson study. Journal of Mathematics Teacher Education, 18(3) 207-229. http://dx.doi.org/10.1007/s10857-014-9282-7

Wu, J. H. y Lin, C. Y. (2017). A multilevel analysis of teacher and school academic optimism in Taiwan elementarys. Asia Pacific Education Review, 19(1), 53-62. https://doi.org/10.1007/ $\underline{\text { s12564-017-9514-5 }}$

Yeh, Y.-C y Lin, C. S. (2018). Achievement goals influence mastery experience via two paths in digital creativity games among elementary school students. Journal of Computer Assisted Learning, 34(3), 223-232. https://doi.org/10.1111/jcal.12234 